\title{
Assessment of Technological Developments in Data Analytics for Sensor-Based and Robot Sorting Plants Based on Maturity Levels to Improve Austrian Waste Sorting Plants
}

\author{
Karl Friedrich * DD, Theresa Fritz, Gerald Koinig, Roland Pomberger and Daniel Vollprecht $(\mathbb{C}$
}

check for updates

Citation: Friedrich, K.; Fritz, T.; Koinig, G.; Pomberger, R.; Vollprecht, D. Assessment of Technological Developments in Data Analytics for Sensor-Based and Robot Sorting Plants Based on Maturity Levels to Improve Austrian Waste Sorting Plants. Sustainability 2021, 13, 9472. https://doi.org/10.3390/su13169472

Academic Editors: Sunil Kumar, Pooja Sharma and Deblina Dutta

Received: 17 June 2021

Accepted: 17 August 2021

Published: 23 August 2021

Publisher's Note: MDPI stays neutral with regard to jurisdictional claims in published maps and institutional affiliations.

Copyright: (c) 2021 by the authors. Licensee MDPI, Basel, Switzerland. This article is an open access article distributed under the terms and conditions of the Creative Commons Attribution (CC BY) license (https:/ / creativecommons.org/licenses/by/ $4.0 /)$.
Chair of Waste Processing Technology and Waste Management, Department of Environmental and Energy Process Engineering, Montanuniversitaet Leoben, 8700 Leoben, Austria; theresa.fritz@unileoben.ac.at (T.F.); gerald.koinig@unileoben.ac.at (G.K.); roland.pomberger@unileoben.ac.at (R.P.); daniel.vollprecht@unileoben.ac.at (D.V.)

* Correspondence: karl.friedrich@unileoben.ac.at; Tel.: +43-3842-402-5139

Abstract: Sensor-based and robot sorting are key technologies in the extended value chain of many products such as packaging waste (glass, plastics) or building materials since these processes are significant contributors in reaching the EU recycling goals. Hence, technological developments and possibilities to improve these processes concerning data analytics are evaluated with an interviewbased survey. The requirements to apply data analytics in sensor-based sorting are separated into different sections, i.e., data scope or consistency. The interviewed companies are divided into four categories: sorting machine manufacturers, sorting robot manufacturers, recycling plant operators, and sensor technology companies. This paper aims to give novel insights into the degree of implementation of data analytics in the Austrian waste management sector. As a result, maturity models are set up for these sections and evaluated for each of the interview partner categories. Interviewees expressed concerns regarding the implementation such as a perceived loss of control and, subsequently, a supposed inability to intervene. Nevertheless, further comments by the interviewees on the state of the waste management sector conveyed that data analytics in their processes would also be a significant step forward to achieve the European recycling goals.

Keywords: sensor-based sorting; robot sorting; data analytics; maturity model; recycling; waste treatment; waste management

\section{Introduction}

Sensor-based sorting, being one of the newest technologies for the recycling industry, is hoped to improve waste sorting enough to lead the way into a digitalized future and subsequently help meet the goals presented by the EU in 2018. These are $70 \%$ for packaging by 2030 and municipal waste in 5-year steps to a minimum of $65 \%$ by 2035 . In addition, landfilling of municipal waste must be ensured to decrease to a maximum of $10 \%$ [1].

In recent years sensor-based sorting became increasingly popular due to the numerous possible applications and advancements in sensor technology as micro technologies enabled mass production of low cost and high-reliability sensors [2,3]. Sensor-based sorting is a contactless automated separation of particles based on specific features. Applications of this method can vary depending on the complexity of the technical design and the number of sensors. The detected features include color, composition, density, and conductivity, and the detection units, while following similar principles, vary in their construction. Comparisons with the still widely applied manual sorting show that sensor-based systems can identify characteristics of waste components more accurately [4-6]. An additional advantage related to mechanical waste sorting is the reduced health risk for workers [7]. The option to combine sensors with different characterization principles [8] especially results in a better quality of the final product, higher product yield and improved valuable recovery [9], 
which are aspects that can correlate directly with a recycling plant's revenue [10,11]. Due to the dynamic development of sensor-based sorting in recent years, new areas for use were and still are found [12-14]. Some sensors detect the superficial properties of the material, others give information about internal characteristics [15]. Visible spectroscopy (VIS) and near-infrared-sensors (NIR) belong to the first group and the other group comprises $\mathrm{X}$-ray-transmission, $\mathrm{X}$-ray-fluorescence, and inductive sensors [16].

Industry 4.0, the IoT, and rapidly increasing digitalization will enable the individual stakeholders (companies, customers, products, among others) to share valuable information amongst themselves in real time [17]. At the same time, the use of IT and automation will ensure the processing, analysis, and collection of vast amounts of information [18].

Implementing Industry 4.0 into the existing value chain of producers and stakeholders, though necessary for remaining responsive and adaptive to increasingly dynamic markets [19], comes with its own set of challenges and demands. When implementing Industry 4.0 technologies, challenges such as implantability, embedment, flexibility, and, especially in the field of waste management, robustness need to be considered [20].

Among the four dimensions of Big Data, namely, the variety of data, the velocity of generation and analysis of new data, the value of data, and the volume of data [21], one of the most pressing issues when adapting an existing plant to an Industry 4.0 approach is the emergence of vast amounts of data that must be processed and transmitted.

Transmission under the current industrial wireless network protocol is infeasible due to the limited bandwidth, which is unsuited to the necessary transmission rates for large scale Industry 4.0 applications [19]. Industry 4.0 needs transmission protocols able to handle the expected increase in data transmission volume.

In addition to the transmission issue, data processing needs to be implemented in a manufacturing-specific manner to ensure high quality and fidelity in the processed data and cohesion among different data acquisition models has to be ensured to allow for big data analytics [22].

Lastly, Industry 4.0 calls for standardized communication protocols and interconnectivity. This increase in connectivity and ease of access through standardized connections leads to issues concerning cybersecurity. The need to protect critical infrastructure, sensitive manufacturing data, and classified information stored in local servers or cloud-based IT platforms [23] increase dramatically with the use of Industry 4.0 settings [24].

The central aspect of Industry 4.0, apart from gaining insight into current industry procedures, is determining the differences in handling data [25] along the sensor-based sorting value chain in waste management. This value chain starts with the sensor manufacturer, which produces the sensor. Next comes the sorting machines manufacturer or the sorting robot manufacturer who installs the sensor in his equipment. At the end of this value chain, the sorting plant operator shows up and installs the sorting machine or sorting robot in his plant.

The definition of data as well as the perceived important aspects and usages may vary between individual stakeholders, thus resulting in unrealized potential concerning the possibilities and advantages of a sound data analytics strategy. Therefore, this study aims to explore the different approaches to and goals of the data handling part of digitalization in each of the four stakeholder categories.

The scientific research questions that are answered in this paper are:

1. How mature is the sensor-based and robot sorting area in Austrian waste management in the use of data analytics?

2. Where are the current limitations in technologies or in the willingness to be able to use data analytics in sensor-based or robot sorting in Austria?

3. What are the risks and chances in the specific area of sensor-based and robot sorting in the Austrian waste management sector?

Scientific literature reviews were performed to find a suitable evaluation method, searching for approaches to similar overarching questions. 
Graninger executed an interview-based survey in his master's thesis to monitor the current status of the interpretation, implementation and obstacles for Industry 4.0 in Austria's industrial sector. In Graninger's study, 34 companies out of over 300 participated in an email-based survey, so the return rate was approximately $10 \%$. Furthermore, only 26 of them filled out this survey completely. The expert interviews were evaluated with bar charts and key figures such as a score factor or the weighted average [26].

Another analogical study was brought up by the German federal ministry of economics and technology in 2013. An online survey to evaluate the innovation potentials of big data was created and sent out to companies over decision makers, providers, users and scientists. It is not stated how many surveys were sent or where the contacted companies are located, but it is mentioned that 185 assessments were returned. The evaluation was done with percentages in bar charts [27].

Schuhmacher et al. created a study for an Industry 4.0 maturity model with expert interviews, practitioner workshops, and literature research. It was evaluated with spider diagrams and weighing of influence factors [28]. A maturity level is a step with predefined characteristics, with each level having more advanced characteristics on the way toward a mature process. In the case of this study, a data analytics strategy embracing all later specified aspects was used.

The last reference study was published by Gonçalves et al. and evaluates the readiness for Industry 4.0 of manufacturing companies. An online self-check tool was created and sent to an unknown number of companies, of which a total of 602 companies responded [29].

All these studies only consider Industry 4.0 in general but do not consider sensorbased sorting as a special technology within Industry 4.0. Therefore, in this study, for the first time ever, a maturity level assessment for sensor-based sorting in waste treatment is carried out with a focus on the Austrian waste sorting sector.

\section{Materials and Methods}

The state-of-the-art in waste sorting plants compared with a literature review revealed that a lot of information on sensor-based sorting in waste treatment is not accessible in the literature and is only known and traded by industrial experts in this field. For this reason, instead of a literature review, expert interviews were selected as an appropriate methodology.

After analyzing the previous stated four studies [26-29], it was decided that an interview-based survey would fit best since more information may be gathered in a personal conversation than from evaluating answers to predefined survey questions alone.

The interview-based survey consisted of questions regarding data analytics in general and in sensor-based/robot sorting. Due to COVID-19, all the interviews were conducted via video calls from March 2020 until May 2020.

The interviewed stakeholder experts were separated into four categories along the sensor sorting value chain: sensor manufacturers, sorting machine manufacturers, sorting robot manufacturers, and sorting plant operators. These categories were selected because only they can provide original data, whereas other stakeholders such as public authorities or research institutions could only provide secondary data obtained from the same group of experts. According to the working hypothesis, the highest maturity level should occur at the sensor technology sector, and at every step of utilization it will decrease, i.e., the sorting robot manufacturer is technologically behind the sensor producer, and so on.

Twenty-eight stakeholder experts were contacted, but due to reduced working hours in many companies, 12 interviews were held. The interview length varied from $45 \mathrm{~min}$ to $2.5 \mathrm{~h}$. These 12 interviewed stakeholder experts cover mainly the whole Austrian waste sorting sector, although the companies are located all in Europe, because their equipment is the most commonly installed in Austrian waste sorting plants. The interviewed stakeholder experts were two sensor manufacturers located in Europe, four sorting machine manufacturers located in Europe, two sorting robot manufacturers located in Europe, and four sorting plant operators located in Austria. 
In this section, it has to be stated that two sensor manufacturers cover the Austrian waste sorting sector because some sorting machine manufacturers produce their own sensors for their sorting machines. The two sorting robot manufacturers also cover the Austrian waste sorting sector since there are only a few sorting robots installed currently.

At the beginning of the interviews, the interviewers introduced themselves (the Chair of Waste Processing Technology and Waste Management), the research area of sensor-based sorting in the industry, as well as the aim and the focus of the survey. Next, the interviewee introduced himself, described his job and responsibilities in his company, and had the opportunity to bring in some questions of interest for the study. An example for such a question would be how the acquired data in the assessment is processed, which was in most of the interviews as the first open question. After it was agreed that the acquired data is only allowed to be published in an anonymous way-which was the precondition for each of the companies to participate-the survey questioning itself started. In some cases, one answer flipped to another question, but it was decided to follow the survey strictly and discuss topics twice instead of assuming the risk of missing any information. Nevertheless, when additional questions came up for some answer, they were discussed and appended to the study's results.

The evaluation of the data acquired in the study is done with individual critical analysis for each of the expert interviews and graphically visualized with bar charts since the number of participants is straightforward and enables going into details with each of the interviewees.

The data analytics survey was primarily based on the doctoral thesis of Bernerstätter [30]. It consisted of general questions, a self-evaluation, and detailed questions, i.e., concerning the consistency and amount of data needed to calculate the degree of data analytics maturity [30]. Bernerstätter stated that a maturity for the use of data analytics cannot be determined with one overall maturity level that is detailed enough because the maturity for data analytics consists of many sectors which need to be determined individually to calculate an overall maturity level. These sectors are data collection, data provision and transfer, data formats, data encoding and presentation, data scope, data consistency, and data usage [30]. In his models, the maturity level 1 is the lowest level and the maturity level 4 the highest, which is also the basis for this study [30]. For this study there was also a new sector considered, which is the commitment to change, to bring in a perspective on whether applying data analytics is not a technical problem but a mental one when employees fear losing their jobs with increasing digitalization.

The first set of introductory questions covers data of sensor-based sorting systems, namely, which data are collected and where they are stored, and aims to determine a degree of occupation with the topic of the data in general Table 1.

The averaged data analytics maturity level is calculated via the summation of the answers divided by the number of questions, with a possible 0.5 gradation if the participants felt that the company was on the way to a higher level but not quite there yet. The self-assessment, which is an estimation of the overall maturity level based on the four possibilities given (Table 2) was done prior to the detailed questions which were used to calculate an average data analytics maturity level with all of the data analytic sectors (Table 3) to compare. Lastly, it was inquired if the industry experts trusted their recorded data. 
Table 1. Questions concerning data collection by the sensor-based sorting system and the general approach to data.

\begin{tabular}{cc}
\hline What Data is Collected by the Sensor-Based Sorting System? \\
\hline Production data & $83 \%(10 / 12)$ \\
Maintenance data & $75 \%(9 / 12)$ \\
Quality data & $58 \%(7 / 12)$ \\
Machine data & $83 \%(10 / 12)$ \\
Other data & $8 \%(1 / 12)$ \\
\hline Where is the data recorded? & $92 \%(11 / 12)$ \\
\hline Right at the plant & $50 \%(6 / 12)$ \\
Measuring room & $8 \%(1 / 12)$ \\
Not on site & $0 \%(0 / 12)$ \\
\hline Others & $83 \%$ yes $(10 / 12)$ \\
\hline Has the company implemented a strategy for managing data? & $50 \%$ yes $(6 / 12)$ \\
\hline Are data owners assigned for data governance? & $75 \%$ yes $(9 / 12)$ \\
\hline Are efforts made as well to ensure high quality of transaction data?
\end{tabular}

Table 2. Self-assessed data analytics maturity level.

\begin{tabular}{|c|c|}
\hline \multicolumn{2}{|c|}{$\begin{array}{c}\text { How Would You Assess the Degree of Maturity of Data Analysis for Sensor-Based Sorting or } \\
\text { Robot } \\
\text { Sorting in Your Company Using the Following Scale? }\end{array}$} \\
\hline $\begin{array}{l}\text { Hardly any digitization in data analysis has been implemented. } \\
\text { There is no actual concern about the subject. }\end{array}$ & 1 \\
\hline $\begin{array}{l}\text { An analysis of interrelationships has been implemented } \\
\text { showing the reasons for an incident. }\end{array}$ & 2 \\
\hline $\begin{array}{l}\text { Partially automated recording and specific formatting standards have been } \\
\text { implemented. However, there is no consistency across data sources. }\end{array}$ & 3 \\
\hline $\begin{array}{l}\text { Continuous data and information management have been implemented based on } \\
\text { established standards. In addition, prescriptive analysis helps the system act } \\
\text { autonomously and appropriately. }\end{array}$ & 4 \\
\hline
\end{tabular}

Table 3. Detailed data analytics maturity level to portray a more accurate state of the art.

\begin{tabular}{cc}
\hline & Data Collection \\
\hline $\begin{array}{c}\text { Data collection does not adhere to any standards and objectives } \\
\text { and, in addition, is incomplete. }\end{array}$ & 1 \\
Paper-recording predominates, the amount of data collected is generally relatively small. & \\
\hline $\begin{array}{c}\text { Digital data collection is triggered manually or irregularly. Fault remedy measures and } \\
\text { logic connecting }\end{array}$ & 2 \\
the process generated and collected data are available. & 3 \\
\hline $\begin{array}{c}\text { Irregular predefined triggers constitute automated data collection. } \\
\text { Manual records are regularly digitized. }\end{array}$ & 4 \\
\hline No more manual data input, only confirmation of values is required. \\
Dutomated data acquisition is made in regular intervals. \\
\hline $\begin{array}{c}\text { Local server systems cause interface and compatibility problems. } \\
\text { aggregation is not ensured. }\end{array}$ \\
\hline
\end{tabular}


Table 3. Cont.

\begin{tabular}{|c|c|}
\hline \multicolumn{2}{|l|}{ Data provision and transfer } \\
\hline $\begin{array}{c}\text { A centralized database system prevents interface problems and enables real-time analysis. } \\
\text { Unstructured data from measurement processes are immediately reduced to } \\
\text { relevant characteristics. }\end{array}$ & 3 \\
\hline $\begin{array}{l}\text { Pre-processing steps are provided to immediately present data in a structured manner } \\
\text { ready for analysis. } \\
\text { Data is stored in a Data Warehouse. }\end{array}$ & 4 \\
\hline \multicolumn{2}{|l|}{ Data formats } \\
\hline It takes high effort to convert the data into a standard format. & 1 \\
\hline $\begin{array}{l}\text { Standard data formats are used (xls, PDF, ... ) but not consistently, } \\
\text { so that compilation takes a lot of time and effort. }\end{array}$ & 2 \\
\hline $\begin{array}{l}\text { Data formats do not limit the common data stock. } \\
\text { Large amounts of data can be stored. }\end{array}$ & 3 \\
\hline $\begin{array}{l}\text { Data formats are irrelevant because the file transfer passes through an interface straight to } \\
\text { an analysis tool. Alternatively, file formats suitable for Big Data are available. }\end{array}$ & 4 \\
\hline \multicolumn{2}{|l|}{ Data encoding and presentation } \\
\hline $\begin{array}{l}\text { Text-only or incomprehensible codes characterize this unstructured } \\
\text { form of data collection. }\end{array}$ & 1 \\
\hline Codes can be interpreted clearly and entries are comparable. & 2 \\
\hline $\begin{array}{l}\text { Unambiguous interpretability is standard; essential attributes are scaled metrically, } \\
\text { enabling transformation into nominally scaled values. }\end{array}$ & 3 \\
\hline $\begin{array}{c}\text { Metadata facilitates the automatic interpretation of the standardized codes } \\
\text { from all data sources. }\end{array}$ & 4 \\
\hline \multicolumn{2}{|l|}{ Data scope } \\
\hline $\begin{array}{c}\text { Data collected is unstructured, partly irrelevant, and too little in number. } \\
\text { Spreadsheet software is sufficient. }\end{array}$ & 1 \\
\hline $\begin{array}{l}\text { The amount of data collected is too large to be interpreted by staff. } \\
\text { The recording period is at least nine months. }\end{array}$ & 2 \\
\hline The recording period is at least one year. & 3 \\
\hline $\begin{array}{l}\text { For at least } 1.5 \text { years, data has been entirely recorded and its relevance checked } \\
\text { by precise allocation to the relevant observation units. }\end{array}$ & 4 \\
\hline \multicolumn{2}{|l|}{ Data consistency } \\
\hline Manual recordings provide inadequate or no consistent time reference. & 1 \\
\hline $\begin{array}{l}\text { Consistent time reference cannot be ensured across data sources } \\
\text { but can be achieved using time stamps. }\end{array}$ & 2 \\
\hline $\begin{array}{l}\text { Diagnostic purposes can be satisfied by a defined reliable interval between surveys (to } \\
\text { provide forecasts). Consistent time reference is ensured even across data sources. }\end{array}$ & 3 \\
\hline $\begin{array}{l}\text { A consistent system ensures time stamp integrity and traceable quality } \\
\text { by association with ID data (e.g., order numbers). }\end{array}$ & 4 \\
\hline \multicolumn{2}{|l|}{ Data usage } \\
\hline $\begin{array}{c}\text { Data is not used, i.e., records are kept without interpretation, or no adjustments are } \\
\text { performed after interpretation. }\end{array}$ & 1 \\
\hline $\begin{array}{l}\text { Individual records are converted into a format ready for interpretation. } \\
\text { Problems with data quality/consistency are known but not remedied in a standardized } \\
\text { way. The IT department is solely responsible. }\end{array}$ & 2 \\
\hline
\end{tabular}


Table 3. Cont.

\begin{tabular}{|c|c|}
\hline \multicolumn{2}{|l|}{ Data usage } \\
\hline $\begin{array}{l}\text { Data is interpreted to remedy faults and to make decisions on a regular basis. } \\
\text { Data management processes are documented and discussed } \\
\text { with data protection and security. } \\
\text { Data is considered a resource. }\end{array}$ & 3 \\
\hline $\begin{array}{c}\text { Both an archiving strategy and a disposal strategy are implemented. } \\
\text { The use and expense of data can be financially evaluated. } \\
\text { Data-based systems intervene in the process. }\end{array}$ & 4 \\
\hline \multicolumn{2}{|l|}{ Commitment to change } \\
\hline $\begin{array}{l}\text { Staff and/or management resist real-time digital measurements, } \\
\text { preferring paper-based recording or simultaneous digital and paper-based data } \\
\text { recording. New technologies are faced with skepticism and no serious measures } \\
\text { are taken to overcome resistance. }\end{array}$ & 1 \\
\hline $\begin{array}{l}\text { Individuals or mid-level management are voicing a desire for change. } \\
\text { Change management is not systematic, } \\
\text { but the relevance of data used as a resource is discussed. }\end{array}$ & 2 \\
\hline $\begin{array}{l}\text { Easy data access and fast interpretation, as well as automated process tracking, are key } \\
\text { elements. Handling of data loss or insufficient data is improved. } \\
\text { The entire management supports change projects and embraces new technologies. }\end{array}$ & 3 \\
\hline $\begin{array}{l}\text { New digital systems are embraced to support staff and to maintain and optimize } \\
\text { the process. Change projects can be initiated top-down and bottom-up. }\end{array}$ & 4 \\
\hline
\end{tabular}

\subsection{Types of Data Recorded}

During the interviews, additional information about the nature of the data collected has been gathered. Despite varying amongst the different stakeholders, similar types of data are being collected across all participating companies. These types of recorded data and a detailed description to them is listed in Table 4 . The data will be categorized into four groups, namely machine, production, maintenance, and quality data.

Table 4. Types of data collected across all participating companies.

\begin{tabular}{l} 
Production Data \\
\hline Occupation density \\
Since the sorting efficiency is highly dependent on the occupation density (quote), many \\
stakeholders opt to record the occupation density. The calculation is done by dividing the number \\
of pixels detected by the area of the specific sorting aggregate. \\
Throughput rate \\
The throughput rate is defined as the amount of material in $\mathrm{kg}^{\circ} \mathrm{or}^{3}$ passing through the sorting \\
aggregate in a specified amount of time. Recording the throughput rate can help calibrate the \\
sorting process to reach the ideal trade-off between yield and purity, highly dependent on the \\
throughput rate [31].
\end{tabular}

\section{Maintenance data}

\section{Operating hours}

Currently, the operating hours of the sorting equipment are being recorded. Nevertheless, so far, none of the interviewees intend to use this data set for advanced maintenance techniques such as prospective or predictive maintenance.

\section{Quality data}

Purity and Yield

Purity is the quotient of valuables in the ejected material. This value, along with yield, is the defining factor for the evaluation of separation success. The yield is defined as the quotient material fraction mass (e.g., PET) in eject multiplied with the related eject concentration and divided by input mass, which is first multiplied with the concentration of the material fraction mass in the input (e.g., PET) [25]. 
Table 4. Cont.

\section{Machine data}

Object statistics

The number of objects recognized by the sensor-based sorting setup defines the object statistics.

Objects are defined as areas of coagulated pixels of a specified minimum area.

Pixels statistics

The number of pixels detected for each specified material. This statistic yields the basis for more advanced statistics such as area density or occupation density.

Bad pixel replacement

Sensors may exhibit defective pixels caused by production. Many sorting software packages come with the ability to exclude or filter those pixels to minimize their effect on the sorting efficiency.

However, in most cases, the number of these faulty pixels is not recorded or not available to the software's user.

Areal density

By calculating the average mass of an object and correlating this with the average amount of pixels detected per object, e.g., a given PET bottle, the areal density of said material can be calculated. This measurement can be used to estimate the number of valuables in the input without the necessity of costly hand sorting or input analysis.

Detection rate

The detection rate defines the number of correctly identified pixels and objects with a custom sorting model relative to the standard settings of the given sorting aggregate.

Valve activity

According to the questioned stakeholders, the activation statistics of the pressurized air valves are being saved in most machine statistics. These may be used to recognize one-sided loading of the sorting aggregate in addition to the pixel statistics.

\begin{tabular}{l} 
Other data \\
\hline When the customer wants to record individual data in his sensor-based sorting machines, this \\
option can be additionally enabled. This data could be, e.g., the used spare parts or how many \\
remote maintenance accesses have been performed since the commissioning of the sensor-based \\
sorting machine.
\end{tabular}

\subsection{Validation of Results}

In order to validate the answers of the companies, site visits were conducted at every second company. During these site visits, selected sorting machines and sensors were conducted to confirm the given maturity level.

\section{Results}

Since 28 stakeholder experts were contacted and 12 interviews were held, a return rate of $43 \%$ could be achieved. As not all the 12 participants own a sensor-based sorting system directly, some answers refer to industry partners or customers. Most of the data collected regards the production and machine data, and nearly all of it is collected right at the plant. The introductory questions showed that most of the surveyed companies have a data managing strategy implemented, but only half have a designated person responsible for it. Transaction data, meaning the continual evaluation of data quality, was important to 75\% of the participants. Questions and answers are listed in Table 1.

The self-assessed data analytics maturity level compared to the calculated average for each sector is shown in Figure 1. Sensor manufacturers have estimated their overall maturity level approximately one degree lower than the assessment resulted, and the same was true of the sorting plant operators. The sorting machine manufacturers' selfassessed maturity level is lower than calculated for two stakeholders and higher for another two stakeholders. In contrast, the sorting robot manufacturers self-assessed themselves higher than the calculation result. The average for all of the stakeholders would be an overall data maturity level between 2.0 and 3.0, which would also be the similar to the self-assessed average. 


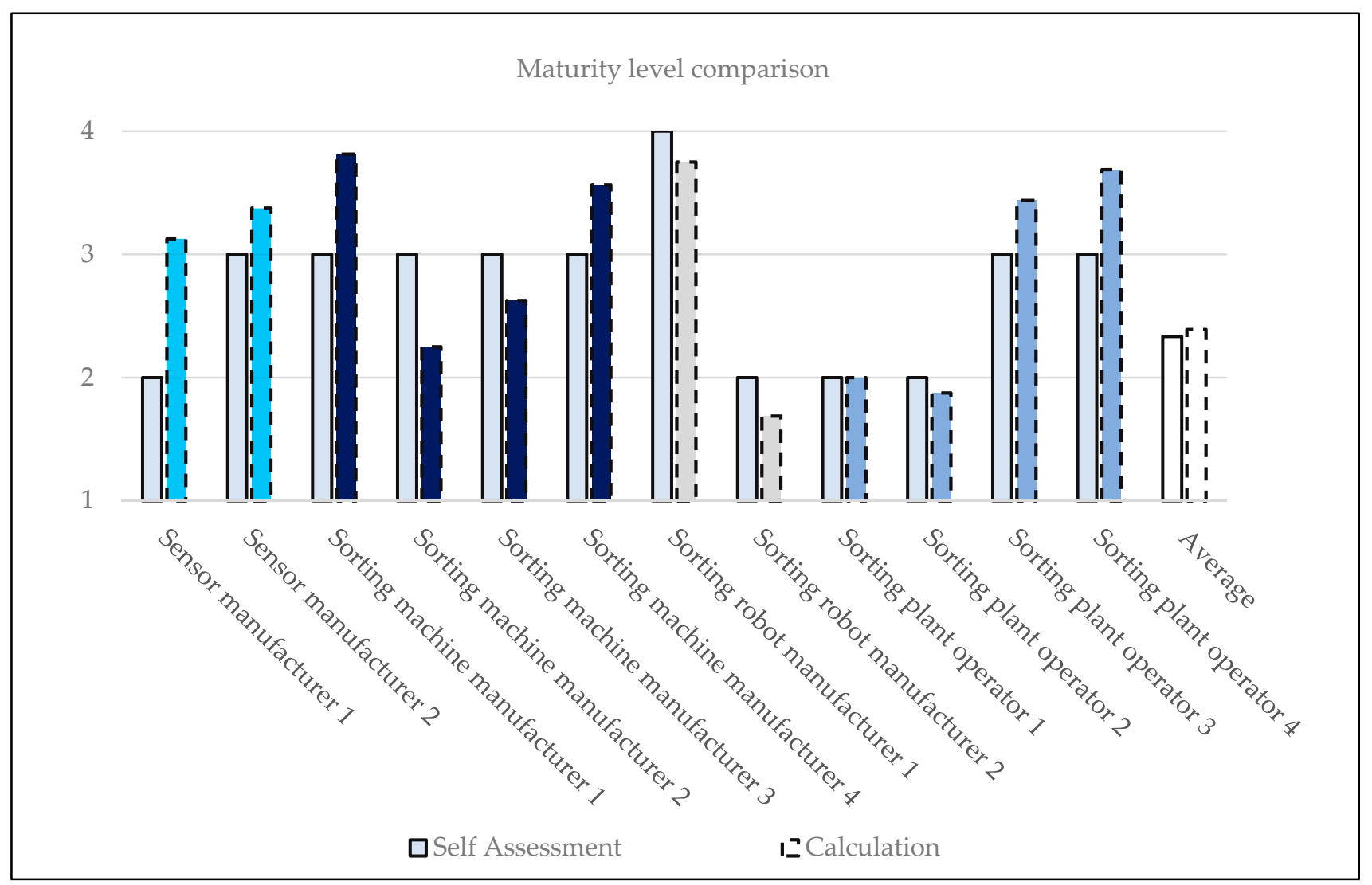

Figure 1. Data analytics maturity level split up into the individual answers of all participants and comparison to the self-assessment.

It was mentioned by the stakeholder experts that smaller and younger companies often do not have the means to build a data management strategy yet and, in addition, presently do not need it. However, all the questioned companies found data analytics to be an important topic that cannot be overlooked in the future and pledged to improve their approach to data handling. The following text will go into detail about which maturity level was calculated for each sector from the overall calculated data analytics maturity level. Figure 2 shows the results for each data analytics sector split up for each stakeholder expert.

Primarily following the data analytics maturity assessment of Bernerstätter [24], the first question for the calculated data analytics maturity level concerns data collection. Most of the participants were identified as being on the third step or higher. The area of data collection was generally considered to be the most digitized, especially for three sorting machine manufacturers and one sorting robot manufacturer, which reached level 4 . Table 3 contains detailed descriptions of all maturity levels for each sector. The third level for data collection is described as 'Irregular predefined triggers constitute automated data collection. Manual records are regularly digitized'. Data use is evidently not automated in plants to optimize efficiency. It is only used manually to optimize the sorting machine efficiency in periodic maintenance or troubleshooting when sorting machines face problems. 
Sensor manufacturer
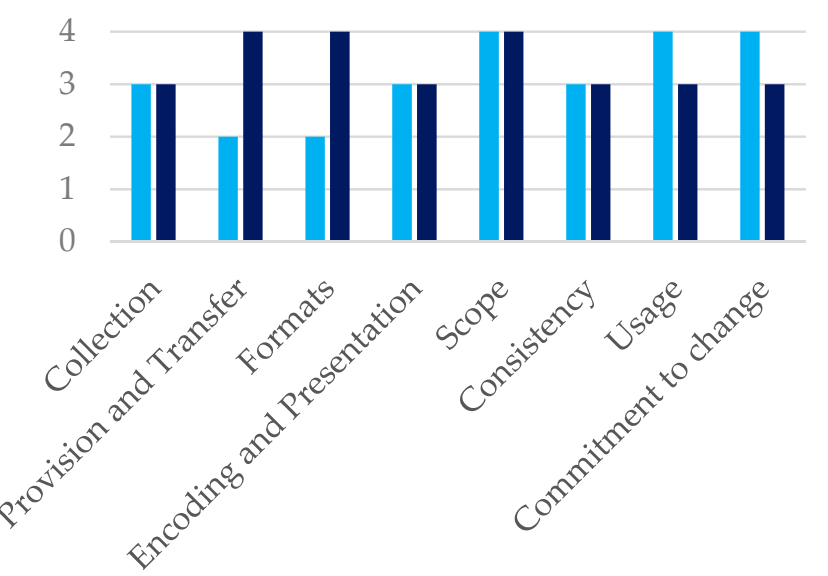

- Sensor manufacturer 1

Sensor manufacturer 2

Sorting robot manufacturer
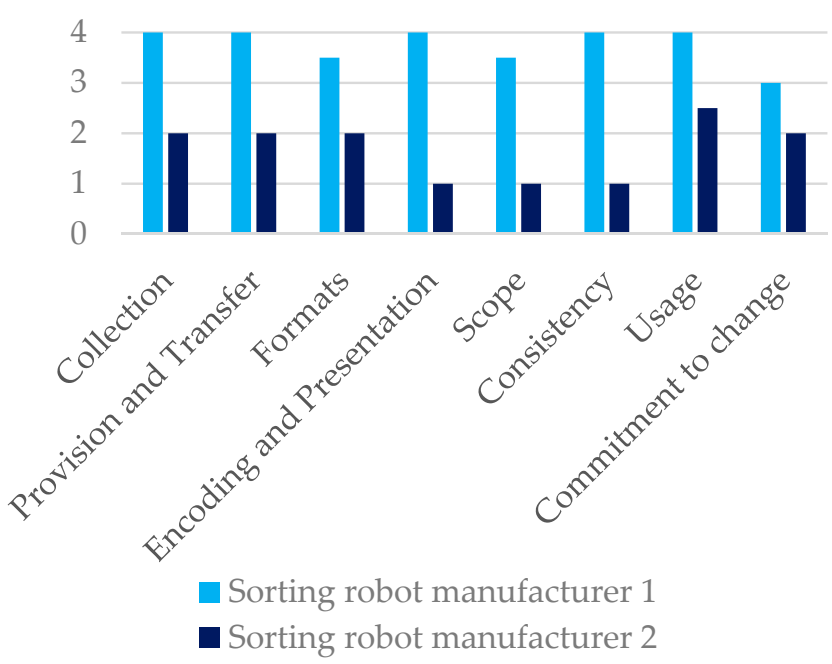

Sorting machine manufacturer
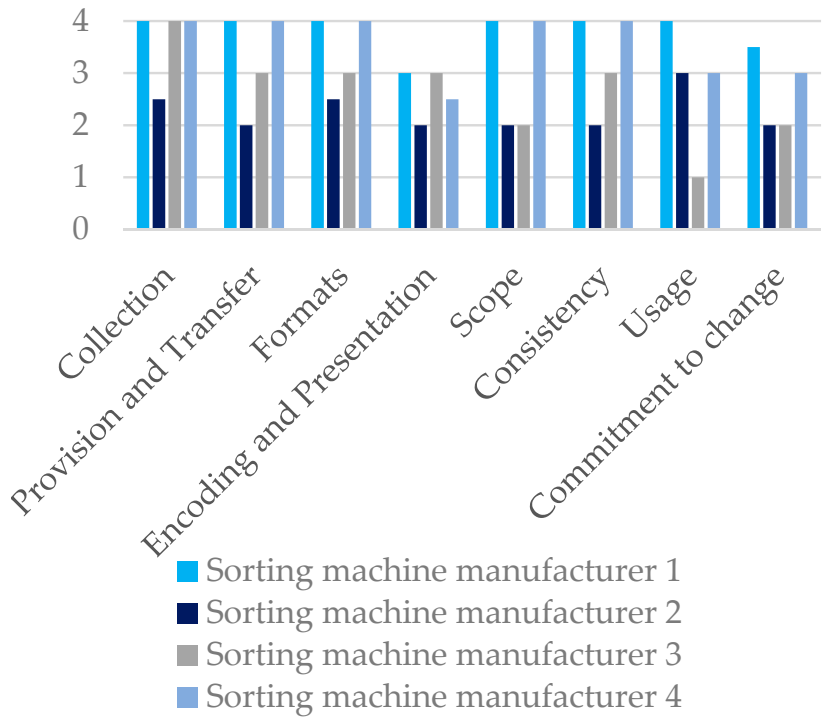

Sorting plant operators
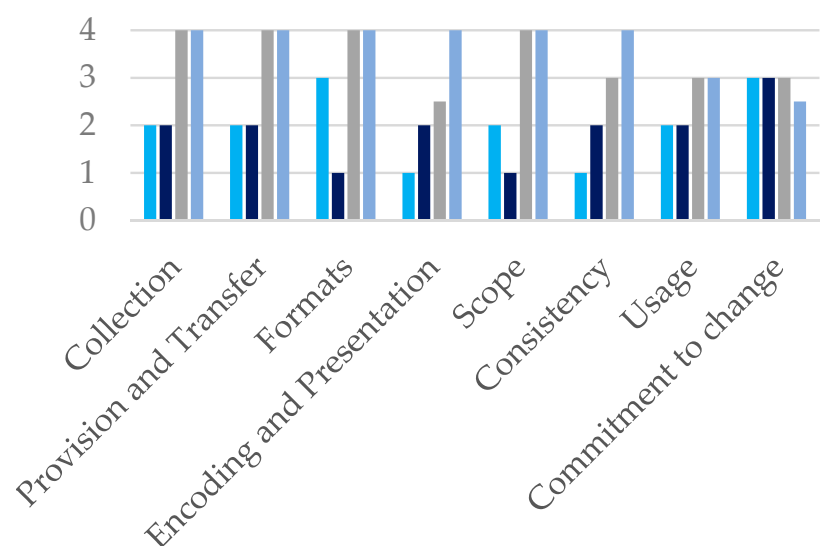

- Sorting plant operator 1

- Sorting plant operator 2

Figure 2. Comparison of the stakeholder answers in maturity levels from one to four in each data analytics category.

Question 2 concerns data provision and transfer and was estimated to be a level 4 for half of the interviewed stakeholder experts through the sensor-based sorting value chain. The description of the fourth level is 'Pre-processing steps are provided to immediately present data in a structured manner ready for analysis. Data is stored in a Data Warehouse'.

Data formats, as a sector of data analytics, show similar results to data provision and transfer instead of sorting machine manufacturer 2, which faces a maturity level of 2.5. The fourth maturity level, which is the dominant one, is defined as 'Data formats are irrelevant because the file transfer passes through an interface straight to an analysis tool. Alternatively, file formats suitable for Big Data are available'.

Generally, there is no visible trend seen for all four stakeholder categories in data encoding and presentation. The most established maturity level in this sector was level 3 (four times), which is defined as 'Unambiguous interpretability is standard; essential attributes are scaled metrically, enabling transformation into nominally scaled values'.

On the data scope, half of the participated stakeholders are on the fourth step with the description 'For at least 1.5 years, data has been entirely recorded and its relevance checked by precise allocation to the relevant observation units'. The maturity level 3 could 
not be achieved by any interviewed stakeholder, and all of them had either a lower or a higher level.

Regarding data consistency, four participants are on the fourth level. The sensor manufacturers are both on second step, defined by the following statement: 'Consistent time reference cannot be ensured across data sources, but can be achieved using time stamps'. An interesting result is that the maturity level of all four interviewed sorting plant operators varies from the lowest level to the highest level.

Consistent with the other maturity levels, the data usage also strongly depends on each interviewed stakeholder individually. The most determined maturity level was level 3 at five stakeholders. The definition for this level is 'Data is interpreted to remedy faults and to make decisions on a regular basis. Data management processes are documented and discussed with data protection and security. Data is considered a resource'.

The last maturity level deviates from the work of Bernerstätter [24] but is also considered to be of interest and concerns the commitment to change. This maturity level does not deal with data but is essential to be considered on the way to a digitized future that does not start and stop at the IT department. Most of the participating stakeholder experts took a second to think about this part and changed their answers at least once. Only sensor manufacturer 1 found himself on the fourth maturity level and sorting machine manufacturer 1 was on the way to the fourth. The other stakeholder experts consider themselves to be on the way to the third, at the second level, or in between. Maturity level 3 is described as follows: 'Easy data access and fast interpretation, as well as automated process tracking, are key elements. Handling of data loss or insufficient data is improved. The entire management supports change projects and embraces new technologies.'

The last question, "Do you trust the recorded data?", received positive answers for 11 out of 12 interviewees ( $92 \%)$, emphasizing the need to verify data permanently. Considering the different maturity levels for each sector and each stakeholder, it cannot be claimed to determine a trend for each sector. However, advancement can be attempted for the whole European waste management industry as the interviewed stakeholders in the categories of sorting machine manufacturers and sorting robot manufacturers hold a considerable share of the market in Europe. Nonetheless, of interest, Figure 2 shows the individual sectors of data analytics in sensor-based sorting and the commitment to change for each stakeholder.

Finally, as a supplementary question, it was asked where there are currently still barriers to the use of data analytics in sensor-based sorting. Ten out of 12 participants stated that, currently, no mathematical relationships or models between the recorded data had been investigated. Whether there can be mathematical models, e.g., describing the influence of the processed data on one another, would first have to be examined. Furthermore, the area of validity for newly found relationships in the recorded data is still not exactly known. Since these mathematical relationships in recorded data are still not investigated on an industrial level, these 10 participants see the use of data analytics as a risk, which can either be a chance or a hazard to a machine and, in the end, may weaken its performance instead of optimizing it. It would be a significant step to investigate the mathematical relationships in the recorded sensor-based sorting machine data to handle this industry's risk correctly.

Furthermore, although the influences of different machine settings are known, they have not yet been investigated on a level that a sensor-based sorting machine can automatically adapt its sorting settings to the material flow to achieve the best sorting results. These settings would be, e.g., the illuminance of the used emitter(s), the used pressure for ejecting, the minimum object area and object height that is discharged, or the delay time for the activation of the compressed air nozzles.

At last, the stakeholders are interested in making sensor-based and robot sorting processes more efficient, either by improving the identification to characterize more particles correctly or by improving sorting efficiency with, e.g., mathematical models. 


\section{Discussion}

The introductory questions generally show high interest in keeping the quality of data high with a minimal tendency to monitor machine and production data in contrast to data concerning the maintenance and quality of the product. In this chapter, the research questions of the study are discussed and interpreted.

4.1. How Mature Is the Sensor-Based and Robot Sorting Area in Austrian Waste Management in the Use of Data Analytics?

In Figure 1, the comparison between the self-assessed and averaged data analytics maturity level, sensor manufacturers and sorting plant operators have estimated their overall maturity level lower than it was calculated in the assessment. Two sorting machine manufacturers self-assessed lower than the results of the assessment and two self-assed higher than the results. Sorting robot manufacturers tend to self-assess themselves a bit higher than the calculated maturity level. The overall average data maturity level for all stakeholders would be between 2.0 and 3.0, which would also be the similar to the self-assessed average.

The maturity levels of each stakeholder in each data analytics sector differ from each other with slight to no correlations, and there is no derivable trend, as can be seen in Figure 2. The maturity level of each data analytic sector strongly depends on the company itself, so the stakeholder categories need to be analyzed individually.

\subsubsection{Sensor Manufacturers}

Sensor manufacturer 1 has been in the market for waste sorting sensors for years and has a broader product portfolio than the sensor manufacturer 2. Sensor manufacturer 2 has a slighter product portfolio, which might be the reason that the data analytic sectors are in the scope and the usage higher for 1 . In provision and transfer, as well as for the formats, the maturity level might be higher for sensor manufacturer 2 since all their sensor portfolio is new and they have already thought about the relevance of these sectors in their product development. Meanwhile, sensor manufacturer 2 still has also "older" sensors in their equipment, which are not supplied with functions of the higher maturity levels. It can be said that new developed sensors are mostly supplied with the opportunity to provide data so that they can be used in sorting plants to develop a smart waste sorting plant.

\subsubsection{Sorting Machine Manufacturers}

For the sorting machine manufacturers, it can be seen that number 1 and number 4 are the leaders for all of the technical categories. The reason for this might be that these two companies are far older than the other two, so the global size of the companies as well as the amount of sold sorting machines result directly in a high maturity level for using data analytics in sensor-based sorting.

Sorting machine manufacturers 2 and 3 are in the lower maturity levels for the sectors, especially sorting machine manufacturer 3 , which has the maturity level of 1 in data usage: 'Data is not used, i.e., records are kept without interpretation, or no adjustments are performed after interpretation'. Taking a closer look on the company itself, it can be determined that this company supplies mostly smaller plants with their equipment, which might be the reason for their lower level: that customers do not favor this option was one of the answers that was given during the interviews. If the customer would have a demand for these options, they would of course integrate such opportunities in their new sorting machine generations. This leads to the next statement, which is that larger sorting machine manufacturers are on a higher data analytics maturity level in nearly all of the sectors than the smaller ones.

\subsubsection{Sorting Robot Manufacturers}

For the sorting robot manufacturers, the same statement as for the sensor manufacturers is valid, but in the other way around. Sorting robots are quite new technologies in the 
waste management branch, so they are developed in a way that data analytics can be used in smart waste sorting plants. The main difference between sorting robot manufacturer 1 and sorting robot manufacturer 2 is that manufacturer 1 developed his robots so that it can be easily integrated in a plant and all of the data can be elected and used by other plant equipment. That is not the intention of sorting robot manufacturer 2: he does not want to share all the data from the robot with other machines, he only provides predefined selected data, which are mostly only finished calculations of objects and pixel statistics. It can be stated that sorting robots are able to provide data so that it can be used in sorting plants to develop a smart waste sorting plant, but this depends-as is also valid for the sensor manufacturers and the sorting machine manufacturers-on which data and how far the supplier is willing to hand over the access to his customer/sorting plant operator.

\subsubsection{Sorting Plant Operators}

The maturity level results of the category of the sorting plant operators shows that sorting plant operators 3 and 4 are further developed than the others. Sorting plant operator 4 is one of the largest waste sorting plants in Austria, which leads to this high maturity level in each category. Sorting plant operator 3 is has new sorting lines and old sorting lines installed and is also much bigger compared to the other sorting plants in Austria. The two smaller sorting plant operators 1 and 2 are not sorting fractions. They only sort out contaminants for waste, which is thermally treated after the sorting. A high maturity level of the data analytic sectors is not required for them since the sorting task is not to obtain a maximized pure sorted output product. They focus is on the legal threshold values for contaminants, which requires, in the worst case, a second sorter to reach the threshold values, but no intelligent plant, which works with cascade connections, uses intelligent circuits or scavenger concepts. In the case of the smaller sorting plants, the investment in a high digitalization level is not required since the tasks are different. For the sorting plant operators, it can be said that there are two main factors: one is the goal of the sorting tasks (high purity of output product or depose contaminants) and the size of the plant, measured in the yearly throughput rate.

In summary, it can be said that new developed sensors are able to provide all requirements to use data analytics in sensor-based and robot sorting. In any case, whether all of these options can be used depends strongly on the knowledge and willingness to share data of the sorting machine or sorting robot manufacturer. Here, as it can be seen in Figure 2, the data analytics sector's commitment to change will be most important for the future. When these two criteria are fulfilled, the last criterion is whether the sorting plant operator wants or needs new innovations to achieve better sorting results as well as the plant size.

4.2. Where Are the Current Limitations in Technologies or in the Willingness to Be Able to Use Data Analytics in Sensor-Based or Robot Sorting in Austria? What Are the Risks and Chances in the Specific Area of Sensor-Based and Robot Sorting in the Austrian Waste Management Sector?

Supplementary questioning discovered the unused potential for further use of data analytics by developing mathematical models and the use of machine learning algorithms. However, the realization of this potential is inhibited by concerns about the reliability of these machine learning technologies. In addition, interviewees voiced their concerns about diminishing control over their machinery, which could lead to adverse effects on the sorting success without them being able to intervene promptly to alleviate the problem. These are viable concerns and must be dealt with in further evaluation of the applicability of machine learning based on mathematical models in the waste processing industry. Simultaneously, further studies have to be conducted to assess the essential machine parameters, e.g., the intensity of the emitters, the used pressure for ejecting, the minimum object area and object height that is discharged or the delay time for the activation of the compressed air nozzles to be controlled. Integrating data analysis systems and intelligent machinery control algorithms backed by mathematical models successfully into the processes would be a significant step into the future for the waste processing industry. The main objective 
of all stakeholders is to make sensor-based and robot sorting processes more efficient by improving either the identification or the mechanical operation with mathematical models.

Author Contributions: Conceptualization, K.F. and D.V.; methodology, K.F.; validation, K.F., T.F. and G.K.; formal analysis, K.F. and T.F.; investigation, K.F. and T.F.; data curation, T.F.; writing-original draft preparation, K.F. and T.F.; writing-review and editing, K.F., T.F. and G.K.; visualization, T.F.; supervision, D.V.; project administration, R.P. All authors have read and agreed to the published version of the manuscript.

Funding: This research received no external funding.

Data Availability Statement: All determined and acquired data is listed in the text of this manuscript.

Conflicts of Interest: The authors declare no conflict of interest.

\section{References}

1. European Union. Implementation of the Circular Economy Action Plan. Report: COM (2019) 190 Final. 2019. Available online: https:/ / eur-lex.europa.eu/legal-content/EN/TXT/?uri=CELEX\%3A52019DC0190 (accessed on 23 August 2021).

2. Kanoun, O.; Trankler, H.-R. Sensor Technology Advances and Future Trends. IEEE Trans. Instrum. Meas. 2004, 53, 1497-1501. [CrossRef]

3. Sparks, D. Application of MEMS Technology in Automotive Sensors and Actuators. Proc. IEEE 1998, 86, 1747-1755. [CrossRef]

4. Wotruba, H. Stand der Technik der Sensorgestützten Sortierung. Berg-Und Hüttenmänn. Mon. 2008, 153, 221-224. [CrossRef]

5. Pretz, T.; Julius, J. Stand der Technik und Entwicklung bei der Berührungslosen Sortierung von Abfällen. (State-of-the-Art and Developments in Contactless Waste Sorting). Österr. Wasser-Und Abfallwirtsch. 2008, 60, 105-112. [CrossRef]

6. Bonello, D.; Saliba, M.A.; Camilleri, K.P. An Exploratory Study on the Automated Sorting of Commingled Recyclable Domestic Waste. Procedia Manuf. 2017, 11, 686-694. [CrossRef]

7. Robert, G.; Marcin, P.; Marek, M. Analysis of Picked up Fraction Changes on the Process of Manual Waste Sorting. Procedia Eng. 2017, 178, 349-358. [CrossRef]

8. Chahine, K.; Ghazal, B. Automatic Sorting of Solid Wastes Using Sensor Fusion. Int. J. Eng. Technol. 2017, 9, 4408-4414. [CrossRef]

9. Küppers, B.; Chen, X.; Seidler, I.; Friedrich, K.; Raulf, K.; Pretz, T.; Feil, A.; Pomberger, R.; Vollprecht, D. Influences and Consequences of Mechanical Delabelling on Pet Recycling. Detritus 2019, 6, 39-46. [CrossRef]

10. Friedrich, K.; Möllnitz, S.; Holzschuster, S.; Pomberger, R.; Vollprecht, D.; Sarc, R. Benchmark Analysis for Plastic Recyclates in Austrian Waste Management. Detritus 2019, 105-112. [CrossRef]

11. Friedrich, K.; Holzschuster, S.; Fritz, T.; Pomberger, R.; Aldrian, A. Benchmark Analysis for Recycled Glass in Austrian Waste Management. Detritus 2020, 87-98. [CrossRef]

12. Curtis, A.; Sarc, R. Real-Time Monitoring of Volume Flow, Mass Flow and Shredder Power Consumption in Mixed Solid Waste Processing. Waste Manag. 2021, 131, 41-49. [CrossRef]

13. Rahman, W.; Islam, R.; Hasan, A.; Bithi, N.I.; Hasan, M.; Rahman, M.M. Intelligent Waste Management System Using Deep Learning with IoT. J. King Saud Univ.-Comput. Inf. Sci. 2020. [CrossRef]

14. Sarc, R.; Curtis, A.; Kandlbauer, L.; Khodier, K.; Lorber, K.; Pomberger, R. Digitalisation and Intelligent Robotics in Value Chain of Circular Economy Oriented Waste Management-A Review. Waste Manag. 2019, 95, 476-492. [CrossRef]

15. Flamme, S.; Hams, S.; Zorn, M. Sensortechnologien in der Kreislaufwirtschaft. Converence Transprict of the 14th Recy-E DepoTechKonferenz; AVAW Eigenverlag: Leoben, Austria, 2018; pp. 787-792, ISBN 978-3-200-05874-3.

16. Beel, H. Sortierung von schwarzen kunststoffen nach ihrer polymerklasse mit hyperspectral-imaging-technologie (sorting of black plastics to their polymer types with hyper-spectral-imaging-technology). In Recycling und Rohstoffe Band 10, Proceedings of Recycling und Rohstoffe; Thomé-Kozmiensky, K.J., Goldmann, D., Eds.; TK-Verlag: Neuruppin, Germany, 2017; pp. 175-191, ISBN 978-3-944310-34-3.

17. Brozzi, R.; Forti, D.; Rauch, E.; Matt, D.T. The Advantages of Industry 4.0 Applications for Sustainability: Results from a Sample of Manufacturing Companies. Sustainability 2020, 12, 3647. [CrossRef]

18. Erhart, W. Digitale Geschäftsmodelle und Schnelle Innovationszyklen in der Traditionellen Industrie. Am Beispiel: Konzeptionierung und Implementierung Eines Digitalen, Mehrseitigen Geschäftsmodells in der Verwertungs- und Entsorgungsbranche (Digital Business Models and Fast Innovation Cycles in the Traditional Industry. Concrete Example: Conceptual Design and Implementation of a Digital, Multilateral Business Model in the Recycling and Disposal Industry). Master's Thesis, FH Campus 02, Graz, Austria, 2017.

19. Antikainen, M.; Uusitalo, T.; Kivikytö-Reponen, P. Digitalisation as an Enabler of Circular Economy. Procedia CIRP 2018, 73, 45-49. [CrossRef]

20. Vaidya, S.; Ambad, P.; Bhosle, S. Industry 4.0-A Glimpse. Procedia Manuf. 2018, 20, 233-238. [CrossRef]

21. Wang, S.; Wan, J.; Li, D.; Zhang, C. Implementing Smart Factory of Industrie 4.0: An Outlook. Int. J. Distrib. Sens. Netw. 2016, 12, 3159805. [CrossRef] 
22. Witkowski, K. Internet of Things, Big Data, Industry 4.0-Innovative Solutions in Logistics and Supply Chains Management. Procedia Eng. 2017, 182, 763-769. [CrossRef]

23. Thoben, K.-D.; Wiesner, S.; Wuest, T. "Industrie 4.0” and Smart Manufacturing-A Review of Research Issues and Application Examples. Int. J. Autom. Technol. 2017, 11, 4-16. [CrossRef]

24. Ivanov, D.; Sokolov, B.; Ivanova, M. Schedule Coordination in Cyber-Physical Supply Networks Industry 4.0. IFAC-PapersOnLine 2016, 49, 839-844. [CrossRef]

25. Rüßmann, M.; Lorenz, M.; Gerbert, P.; Waldner, M.; Engel, P.; Harnisch, M.; Justus, J. Industry 4.0: The Future of Productivity and Growth in Manufacturing Industries; Boston Consulting Group: Boston, MA, USA, 2015.

26. Graninger, G. Industrie 4.0 in der Österreichischen Industrie-Interpretation, Umsetzung, Hindernisse (Industry 4.0 in the Austrian Industry-Interpretation, Implementation, Obstacles). Master's Thesis, Montanuniversität Leoben, Leoben, Austria, 2017.

27. Markl, V.; Löser, A.; Hoeren, T.; Krcmar, H.; Hemsen, H.; Schermann, M.; Gottlieb, M.; Buchmüller, C.; Uecker, P.; Bitter, T. Innovationspotentialanalyse für die Neuen Technologien für das Verwalten und Analysieren von Großen Datenmengen (Big Data Management); Bundesministerium für Wirtschaft und Technologie: Berlin, Germany, 2013; p. 44.

28. Schumacher, A.; Nemeth, T.; Sihn, W. Roadmapping towards Industrial Digitalization Based on an Industry 4.0 Maturity Model for Manufacturing Enterprises. Procedia CIRP (2019) 79. In Proceedings of the 12th CIRP Conference on Intelligent Computation in Manufacturing Engineering, Gulf of Naples, Italy, 18-20 July 2018; pp. 409-414. [CrossRef]

29. Machado, C.G.; Winroth, M.; Carlsson, D.; Almström, P.; Centerholt, V.; Hallin, M. Industry 4.0 Readiness in Manufacturing Companies: Challenges and Enablers towards Increased Digitalization. Procedia CIRP 81 (2019). In Proceedings of the 52nd CIRP Conference on Manufacturing Systems (CMS), Ljubljana, Slovenia, 12-14 June 2019; pp. 1113-1118. [CrossRef]

30. Bernerstätter, R. Reifegradmodell zur Bewertung der Inputfaktoren für Datenanalytische Anwendungen-Konzeptionierung am Beispiel der Schwachstellenanalyse (Maturity Model to Evaluate the Input Factors for Data Analytics Application-ConceptionalDesign Exampled on the Weak Point Analysis). Ph.D. Thesis, Montanuniversität Leoben, Leoben, Austria, 2019.

31. Küppers, B.; Schlögl, S.; Friedrich, K.; Lederle, L.; Pichler, C.; Freil, J.; Pomberger, R.; Vollprecht, D. Influence of Material Alterations and Machine Impairment on throughput Related Sensor-Based Sorting Performance. Waste Manag. Res. 2020, 39, 122-129. [CrossRef] [PubMed] 